\title{
Organic rankine cycle and steam turbine for intermediate temperature waste heat recovery in total site integration
}

\author{
Norhafiza Kamarudin a, Liew Peng Yen a, b, ${ }^{*}$, Nurfatehah Wahyuny Che Jusoh a, Wai Shin Ho b, c, \\ Jeng Shiun Lim ${ }^{b, c}$
}

a Malaysia - Japan International Institute of Technology (MJIIT), Universiti Teknologi Malaysia, Jalan Sultan Yahya Petra, 54100 Kuala Lumpur, Malaysia

b Process System Engineering Center (PROSPECT), Research Institute of Sustainable Environtment (RISE), Universiti Teknologi Malaysia, 81310 UTM Johor Bahru, Johor, Malaysia

c Faculty of Chemical and Energy Engineering, Universiti Teknologi Malaysia, 81310 UTM Johor Bahru, Johor, Malaysia

* Corresponding author: pyliew@gmail.com

\section{Article history}

Received 5 May 2018

Revised 1 June 2018

Accepted 2 July 2018

Published Online 4 February 2019

\section{Graphical abstract}

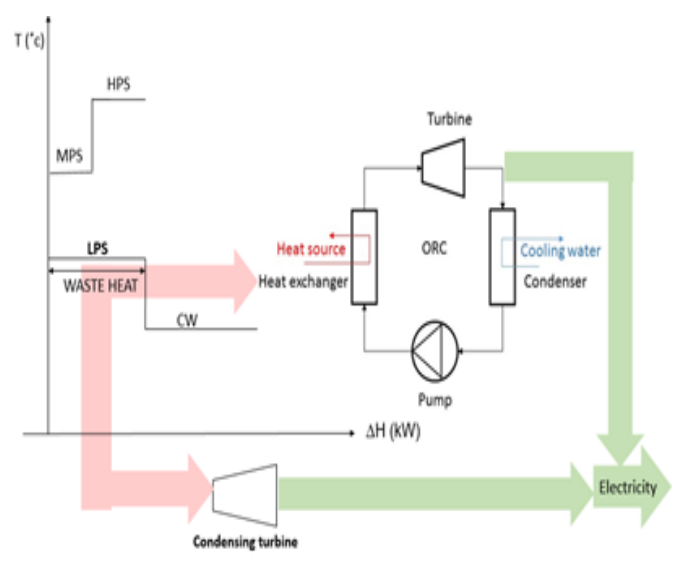

\begin{abstract}
The utilization of waste heat for heat recovery technologies in process sites has been widely known in improving the site energy saving and energy efficiency. The Total Site Heat Integration (TSHI) methodologies have been established over time to assist the integration of heat recovery technologies in process sites with a centralized utility system, which is also known as Total Site (TS). One of the earliest application of TSHI concept in waste heat recovery was through steam turbine using the popular Willan's line approximation. The TSHI methodologies later were extended to integrate with wide range of heat recovery technologies in many literatures, whereby Organic Rankine Cycle (ORC) has been reported to be the one of the beneficial options for heat recovery. In general, the medium to high temperature waste heat is recovered via condensing/backpressure steam turbine, whereas ORC is targeted for recovering the low temperature waste heat. However, it is known that condensing turbine is also abled to generate power by condensing low grade steam to sub-ambient pressure, which is comparable with ORC integration. In this work, the integration of ORC and condensing turbine was considered for a multiple-process system to recover intermediate temperature waste heat through utility system. This study presented a numerical methodology to investigate the performance analysis of integration of ORC and condensing turbine in process sites for recovering waste heat from a centralized utility system. A modified retrofit case study was used to demonstrate the effectiveness application of the proposed methodology. The performances of ORC and condensing steam turbine were evaluated with the plant total utility costing as the objective function. The turbine integration was found to be more beneficial in the modified case study with lower utility cost involved. However, the capital cost has not been considered in the analysis.
\end{abstract}

Keywords: Industrial energy system, organic rankine cycle, steam turbine, combined heat and power $(\mathrm{CHP})$, total site heat integration, low grade heat recovery

\section{INTRODUCTION}

Industrial sector has been identifed as one of the main key players of world energy consumer. The largest heat source losses is reported from power plant and industrial processes (Bendig et al., 2013). Waste heat losses is found to be one of the main reasons of this issue, besides the energy system efficiencies. This large amount of waste heat is not recovered in two temperature ranges, low $\left(120^{\circ} \mathrm{C}\right)$ and extremely high $\left(870{ }^{\circ} \mathrm{C}\right)$ (Thekdi and Nimbalkar, 2014). The lack of wide-scale heat recovery in these two temperature ranges appears to be primarily due to issues associated with technology, materials, and economics (Thekdi and Nimbalkar, 2014). This causes large amount of low-temperature waste heat to be discharged because of its poor ease of use and high cost.
The low temperature waste heat exploitation in process sites can lead to improved site energy efficiency and energy saving through the reduction of hot and cooling utility loads. Total Site Heat Integration (TSHI) methodologies have been long assisted in the integration of heat recovery in plant (industrial site) by considering multiple processes or also known as Total Site. TSHI makes use of indirect heat transfer for inter-process heat recovery targeting using a centralized utility system which is more cost effective in a large scale process industry. Generally TSHI methodology can be divided into graphical, numerical and mathematical program approaches. The numerical targeting algorithm based TSHI is a tool for estimating the maximum TS system waste heat recovery (Liew et al., 2012). The tool is able to assist the identification of the low temperature waste heat amount in overall site with higher 
accuracy compared to the graphical approach, as well as more user friendly than mathematical program approach.

Organic Rankine Cycle (ORC) is one of the waste heat recovery technologies that have been developed to recover low temperature waste heat with its working fluid having boiling point lower than water. By converting low temperature waste heat into power generation, ORC can improve the energy efficiency in various industrial applications through waste heat recovery in the processes site. The benefits of ORC include simple mechanism, low pressure requirement, convenience of maintenance, better economy, and high recovery efficiency(Sun et al., 2017). Methodologies for the ORC design and integration play a crucial role for successful applications of ORC in process sites waste heat recovery. Oluleye and Smith (2016) developed Mixed Integer Linear Programming (MILP) to integrate various thermodynamic cycles which include ORC for waste heat utilization in process site. Oluleye et al. (2016) also proposed a methodology to identify the heat source in a site through graphical approach, however the techno-economic analysis was not evaluated.

The TSHI integration with backpressure turbine and condensing steam turbine are established for medium to high temperature heat recovery. Klemeš et al. (1997) extended TSHI concept for cogeneration targeting but was limited to high temperature heat recovery only. Desai and Bandyopadhyay (2009) proposed a typical steam-based cogeneration system that consisted of boiler for steam production and turbines for power generation through graphical approach. In fact, heat recovery from low pressure steam is worth for consideration through a condensing steam, which reduces the steam pressure to a saturated pressure of room temperature.

The previous literatures on TSHI methodologies application in waste heat recovery were established through graphical and mathematical program approaches (Pierobon et al., 2013). Heat pump has been integrated in Total Site by Liew and Walmsley (2016) using numerical based TSHI methodology, which utilised medium to high temperature waste heat recovery.

In this paper, the effectiveness of the Total Site integration with ORC and condensing steam turbine was explored. A numerical targeting algorithm based TSHI methodology was used to simulate the integration of Organic Rankine Cycle and condensing steam turbine for low temperature waste heat recovery in Total Site processes site. The economic analyses for the ORC and condensing turbine were also evaluated in the developed methodology. The integration of ORC and condensing steam turbine to Total Site was discussed and compared through a case.

\section{METHODOLOGY}

In this paper, the TSHI methodology was extended for two low temperature heat recovery technologies which were ORC and condensing steam turbine. The proposed of extended TSHI methodology would allow low temperature waste heat recovery through integration with the utility system using Low Pressure Steam (LPS). There were three key steps inolved in the extended TSHI methodology. The initial key step was the identification and determination of low temperature waste heat for multiple process involved in the plant using numerical algorithm based TSHI targeting methodology (Liew et al., 2012). The second key step was followed ORC modelling (Aneke et al. (2011) and condensing turbine modelling (Varbanov et al. (2004). This step was crucial to determine the effect of ORC and condensing steam turbine integration in total energy demands of the processes by recovery low temperature waste heat. The last step was economic analysis by determining the plant power generation of profit and plant utility saving. The results for both ORC and condensing turbine would be compared with each other. Figure 1 summarises the overall procedure for the extended TSHI Methodology for both ORC and condensing steam turbine.

KEY STEP 1: Identification and determination of low temperature waste heat

The numerical algorithm based TSHI targeting methodology involves several steps in order to efficiently quantify the amount of low temperature waste heat in the the processes site (Liew et al., 2012). The first step is to construct Problem Table Algorithm (PTA) for individual processes, followed by Multiple Utility-PTA (MU-PTA) and Total Site Problem Table Algorithm (TS-PTA).

In order to determine the energy requirement of an individual process, the construction of the PTA is required based on the process stream data. The heat availability at high temperature interval is cascaded from top to bottom. The hot utility requirement is adjusted until the pinch point shows zero heat cascade is obtained. The top heat flow represents minimum hot utility and the bottom heat flow represents minimum cold utility.

The energy targeting result of PTA shows the ultimate hot and cold utility temperature, which is available at the highest and lowest temperatures respectively. A MU-PTA is required for targeting the requirement of utilities at appropriate temperature according to the process temperature profile, which is typically illustrated in Grand Composite Curve (GCC) in graphical Pinch Analysis. The total of different hot and cold utilities should be equal to the hot and cold utility requirement in PTA. The multiple utility target is then used for determining the energy requirement for different processes in a TS system.

The net heat source and net heat sink of each utility determined in the MU-PTA for individual process are used in the TSHI targeting using TS-PTA. The net heat requirement for each utility level is formulated by deducting total cooling requirement (net heat source) with total heating requirement (net heat sink). Initial cascade is performed with an assumption of zero hot utility. Negative amount of heat represents heat deficit and positive amount of heat represents heat surplus. The resulting heat flow is all positive figures, showing a feasible PTA. If a negative figure is obtained, the most negative figure (if there are more than 1 negative figure) is selected and provide external hot utility with positive value of the same absolute figure is provided at the most top heat flow. The heat is then cascaded down again. The heat value at the bottom of the cascade represents total utility cooling.

KEY STEP 1:Identification and determinationn of low temperature waste heat in Total Site

1) Perform Problem Table Algorithm (PTA) for all individual processes

2) Perform Multiple Utility Problem Table Algorithm (MU-PTA) for all individual processes

3) Perform Total Site Problem Table Algorithm (TS-PTA)

KEY STEP 2: Integration of heat recovery technology
1) ORC modelling and simulation
2) Condensing steam turbine model simulation
KEY STEP 3: Economic analysis
Determination plant utility costing for hot utility, cold utility and
power generation profit

Figure 1 Methodology Summary

\section{KEY STEP 2 : Integration of heat recovery technologies}

There are two types of heat recovery technology to be considered in this work, which include Organic Rankine Cycle and condensing steam turbine. Both of the system are required to be simulated in mathematical expression for relating the inlet and outlet of the mass and energy flow in the system. 


\section{a) ORC model}

The ORC model in this study allows the waste heat integration into the ORC evaporator. The ORC model is developed based on simple thermodynamic relations using EXCEL software relating the power generation with low temperature waste heat availabilty in process sites (Aneke et al., 2011; Cengel and Boles, 2002).

Figure 2 shows a schematic diagram of basic ORC. A typical ORC consists of a pump, an evaporator, a turbine and a condenser. The cycle starts when the working fluid enters the pump at state 1 as saturated liquid and is pressurized to an evaporator. In ideal ORC cycle, the working fluid is compressed isentropically inside the pump to the operating pressure of the heat exchanger. However, in real ORC cycle, the pump efficiency may reduce due to irreversibility.

The deviation of actual pumps from the isentropic ones can be estimated by utilizing pump efficiency defined as:

$$
n_{P}=\frac{\left(h_{2 I}-h_{1}\right)}{\left(h_{2}-h_{1}\right)}
$$

Where $\mathrm{n}_{\mathrm{P}}$ is the pump isentropic efficiency, $\mathrm{h}_{i}$ is the enthalpy in state $i$ and $\mathrm{h}_{i \mathrm{I}}$ is the isentropic enthalpy in state $i$.

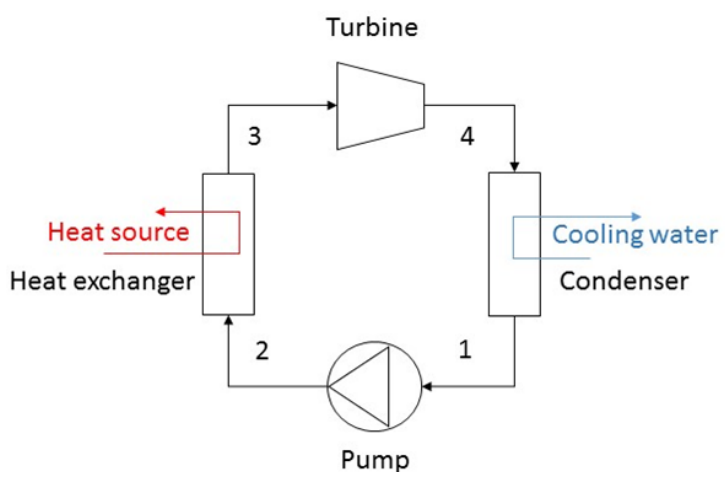

Figure 2 Components in basic ORC.

The pump work input, $\mathrm{W}_{\mathrm{p}}$ is calculated based on following equation:

$$
W_{P}\left(\frac{k J}{k g}\right)=V_{1}\left(P_{I}-P_{2}\right)
$$

The actual pump work input by accounting isentropic efficiency:

$$
W_{p}\left(\frac{k J}{k g}\right)=\frac{V_{1}\left(P_{I}-P_{2}\right)}{\left(n_{p}\right)}
$$

The actual specific enthalpy in state 2 is calculated as follows:

$$
h_{2}\left(\frac{k J}{k g}\right)=\frac{V_{1}\left(P_{2}-P_{1}\right)}{\left(n_{p}\right)}+h_{1}
$$

Where $\mathrm{V}_{i}$ is the specific volumetric in state $i, \mathrm{P}_{i}$ is the pressure at state

Working fluid enters the evaparator as a compressed liquid at stage 2 and leaves as saturated steam or superheated steam. During this process, working fluid is heated up at a constant pressure by exchanging heat with the low temperature waste heat source carrier, the Low Pressure Steam (LPS). The scope of waste heat in this study is the heat which is available above the LPS temperature in the Total Site Profile (Klemeš et al., 1997) after accounting the minimum heating and cooling requirement in the the plant. In order to integrate the waste heat (LPS) into ORC, the amount of waste heat, $\mathrm{Q}_{\mathrm{H}}$ estimated is fed into the evaporator with maximum pinch point difference, $\Delta \mathrm{T}_{\mathrm{PH}}=10^{\circ} \mathrm{C}$.

The amount of heat transferred into the evaparator is expressed as:

$$
Q_{H}\left(\begin{array}{c}
k J \\
k g
\end{array}\right)=m_{o r c}\left(h_{3}-h_{2}\right)
$$

Where $\mathrm{QH}_{\mathrm{H}}$ is is the waste heat amount, morc is the mass floware of working fluid in ORC

Thus the amount of ORC working fluid required to satisfy the heat transfer as follows:

$$
m_{O R C}\left(\frac{k g}{s}\right)=\frac{\left(h_{3}-h_{2}\right)}{Q_{H}}
$$

The working fluid then enters the turbine at state 3 where it expands and produces work by rotating the shaft connected to an electric generator. For an ideal case, the working fluid expands isentropically but it is not the same in an actual case. During the expansion, only a part of the energy recoverable from the pressure difference is transformed into useful work. The other part is converted into heat and is lost.

The efficiency of the turbine, $\mathrm{n}_{\mathrm{T}}$ is defined by comparison with an isentropic expansion in following equation:

$$
n_{T}\left(\frac{k J}{k g}\right)=\frac{\left(h_{3}-h_{4}\right)}{\left(h_{3}-h_{4 I}\right)}
$$
by:

The power generation, $\mathrm{W}_{\mathrm{T}}$ generated by the turbine is determined

$$
W_{T}\left(\frac{k J}{k g}\right)=\left(h_{3}-h_{4}\right)
$$

The net power generated, $\mathrm{W}_{\text {net }}$ by the $\mathrm{ORC}$ in the plant is determined using:

$$
W_{\text {net }}(k J)=m_{O R C}\left(W_{\text {net }}\right)
$$

The thermal efficiency of a cycle is the ratio of the net work output to the heat input, and it is determined as follows:

$$
n_{T}\left(\frac{k J}{k g}\right)=\frac{\left(W_{T}-W_{P}\right)}{Q_{H}}
$$

The model is simulated by using design parameter used in Aneke et al. (2011) ORC model. The data used in (Aneke et al., 2011) is taken from Chena Power Plant. The ORC model output is then validated with Aneke et al. (2011).

$$
1096.845 \mathrm{n} / \mathrm{a}
$$

$$
1096.845 \mathrm{n} / \mathrm{a}
$$

\section{$947.075 \quad 149.77$}

\section{b) Condensing steam turbine model}

An improved steam turbine model is proposed in Varbanov et al. (2004), which has high modelling precision and result confidence. The paper also proposed the regression data based on real device performance data.

In general, the maximum shaft power (electricity generation) of the steam turbine can be related to the the isentropic power through the overall turbine efficiency, as follows:

$$
W_{i s, \max }=\Delta h_{i s} \cdot W_{\max }=W_{\max } / \eta_{s t, \max }
$$

In this study, the steam turbines models are assumed to be part-load model, which effects on the turbine efficiency. The expression of Willian's line is represented as follows:

$$
W_{\text {max }}=n \cdot m_{\text {max }}-W_{\text {int }}
$$


Where $n$ is the slope of the willian's line, $m_{\max }$ is the maximum stream mass flow throgh a steam turbine and $W_{\text {int }}$ is the intercept of the Willian's line.

The intecept of Willian's line can also relate to a turbine interception ratio, $L$, and the maximum power generation, as indicated in e.q.(14). Thus, the maximum power generation can be rewritten as e.q. (15).

$$
\begin{gathered}
W_{\text {int }}=L \cdot W_{\text {max }} \\
W_{\text {max }}=\left(n \cdot m_{\text {max }}\right) /(L+1)
\end{gathered}
$$

The slope of the Willian's line, $n$, can be expressed as follows:

$$
n=\frac{L+1}{B} \cdot\left(\Delta h_{i s}-\frac{A}{m_{\max }}\right)
$$

The parameters $A$ and $B$ are the intermediate regression parameter in the steam turbine model. These parameters require regression analysis from real data, which is based on the saturation temperature difference across the turbine that contributes as the equivalent to the pressure drop across the turbine. The parameters $A$ and $B$ are expressed as follows:

$$
\begin{aligned}
& A=a_{0}+a_{1} \cdot \Delta \mathrm{T}_{\text {sat }} \\
& B=a_{2}+a_{3} \cdot \Delta T_{\text {sat }}
\end{aligned}
$$

The steam turbine intercept ratio for calculation of the Willian's line coefficients, $L$, is also requires in the model, which is also known as proportionality coefficient, as follows:

$$
L=a_{L}+b_{L} \cdot \Delta T_{\text {sat }}
$$

The condensing steam turbine model regression cofficients are recorded in Table 1 (Varbanov et al., 2004), which ranges between 8.232 MW and 59.298 MW.

Table 1 Regression coefficient for condensing steam turbine (Varbanov et al., 2004)

\begin{tabular}{lll}
\hline Coefficient & unit & Value \\
\hline$a_{0}$ & $\mathrm{MW}$ & $-2.080 \times 10^{-8}$ \\
$a_{1}$ & $\mathrm{MW} /{ }^{\circ} \mathrm{C}$ & $2.970 \times 10^{-4}$ \\
$\mathrm{a}_{2}$ & & 1.602 \\
$\mathrm{a}_{3}$ & $1 /{ }^{\circ} \mathrm{C}$ & $0.160 \times 10^{-2}$ \\
$\mathrm{a}_{L}$ & & -0.010 \\
$b_{L}$ & $1 /{ }^{\circ} \mathrm{C}$ & $3.260 \times 10^{-4}$ \\
\hline
\end{tabular}

\section{KEY STEP 3: Economic Analysis}

All the utility requirements determined from the TS-PTA are used to calculate the plant annual utility costing. The estimation of utility costing for High Pressure Steam (HPS), Medium Pressure Steam (MPS), Low Pressure Steam (LPS), Cooling Water (CW) and power generation profit are calculated using equations described as following.

\section{a) Hot Utility Costing Estimation}

In order to calculate the plant hot utility costing, the first step is to calculate the cost of generating steam from the boiler. The fuel cost consists as much as $90 \%$ of the total steam costing while remaining costs are the individual cost components .

The steam costing can be calculated using following equation:

$$
\begin{aligned}
& \text { Fuel } \\
& \text { rate }
\end{aligned}
$$

Where $\mathrm{H}_{\text {steam }}$ is the steam enthalpy at saturation pressure, $\mathrm{H}_{\text {feedwater }}$ is the feedwater enthalpy.

The fuel consumption cost is determined by:

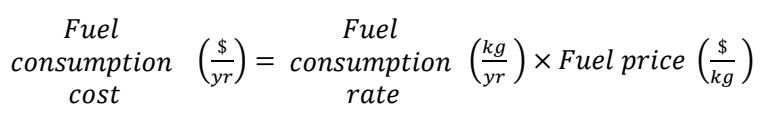

The total steam costing is given by equation:

$$
\begin{aligned}
& \text { Total } \\
& \text { Steam } \\
& \text { Costing }
\end{aligned}\left(\frac{\$}{y r}\right)=\text { Fuel consumption cost }\left(\frac{\mathrm{kg}}{\text { year }}\right) \times(1+0.3)
$$

\section{b) Cold utility costing estimation}

The cooling water $(\mathrm{CW})$ utility price is determined using the following equation (Ulrich and Vasudevan, 2006).

$$
\begin{aligned}
& \text { CW price }\left(\frac{\$}{m^{3}}\right)=\left((0.00007+2.5) \times 10-5 q^{-1}\right)(C E C P I)+ \\
& 0.03 \times \text { Fuel price }\left(\frac{\$}{G j}\right)
\end{aligned}
$$

Whereby q is total water capacity $\left(\frac{\mathrm{m}^{3}}{\mathrm{~s}}\right)$ abd CE CP is the US project inflamation parameter.

The cooling water cost can be calculated based on following,

$$
C W \operatorname{cost}\left(\frac{\$}{y r}\right)=C W \text { price }\left(\frac{\$}{m^{3}}\right) \times \dot{m} C W\left(\frac{m^{3}}{y r}\right)
$$

Where $\mathrm{m} \mathrm{CW}$ is the volumetric flowrate of cooling water.

\section{c) Power generation costing estimation}

The power generation profit of the Organic Rankine Cycle and the condensing turbine can be determined using following equation,

$$
\begin{aligned}
& \text { Electricity price }\left(\frac{\$}{k W h}\right)=1.3 \times 10^{-4}(C E C P 1)+0.01 \times \\
& \text { Price of fuel }\left(\frac{\$}{G j}\right) \\
& \text { Electricity profit }\left(\frac{\$}{\text { year }}\right)=\text { Electricity price }\left(\frac{\$}{k W h}\right) \times \\
& \text { Electricity generation }\left(\frac{k W h}{\text { year }}\right)
\end{aligned}
$$

\section{CASE STUDY}

A modified literature case study (Liew et al., 2012) was used to illustrate the comparison of power generation by ORC and steam turbine. The stream data for the case study was shown in Table 2. There were four utilities available in the TS system, which including High Pressure Steam (HPS $-270^{\circ} \mathrm{C}$ ), Medium Pressure Steam (MPS - 180 ${ }^{\circ} \mathrm{C}$ ), Low Pressure Steam (LPS $-134{ }^{\circ} \mathrm{C}$ ), and Cooling Water $(\mathrm{CW}-$ 15-20 ${ }^{\circ} \mathrm{C}$ ). The minimum temperature difference between utility and process $\left(\Delta \mathrm{T}_{\text {min,up }}\right)$ in this case study was assumed to be $20^{\circ} \mathrm{C}$.

Table 2 Process A stream data for case study (Liew et al., 2012).

\begin{tabular}{lllll}
\hline Stream & $\begin{array}{l}\text { Supply } \\
\text { temp., } \\
T_{s}\left({ }^{\circ} \mathrm{C}\right)\end{array}$ & $\begin{array}{l}\text { Target } \\
\text { temp., } \\
\left({ }^{\circ} \mathrm{C}\right)\end{array}$ & $\begin{array}{l}\text { Heat } \\
\text { duty, } \Delta \mathrm{H} \\
(\mathrm{MW})\end{array}$ & $\begin{array}{l}\text { Heat capacity, } \\
\mathrm{mCp}\left(\mathrm{MW} /{ }^{\circ} \mathrm{C}\right)\end{array}$ \\
\hline Process $\mathrm{A}\left(\Delta T_{\min , \mathrm{pp}}=2{ }^{\circ} \mathrm{C}\right)$ & & \\
\hline A1 Hot & 200 & 100 & 1150 & 10 \\
A2 Hot & 150 & 60 & 3600 & 40 \\
A3 Cold & 50 & 120 & 3150 & 45 \\
A4 Cold & 50 & 220 & 2550 & 15 \\
\hline Process B $\left(\Delta T_{\min , \mathrm{pp}}=10{ }^{\circ} \mathrm{C}\right)$ & & \\
\hline B1 Hot & 200 & 50 & 450 & 3 \\
B2 Hot & 240 & 100 & 210 & 1.5 \\
B3 Hot & 200 & 119 & 1860 & 23 \\
B4 Cold & 30 & 200 & 680 & 4 \\
B5 Cold & 50 & 250 & 400 & 2 \\
\hline
\end{tabular}

\section{KEY STEP 1: Determination of low temperature waste heat in Total Site}

Through the construction of PTA for both processes, Process A minimum hot utility required was $1500 \mathrm{MW}$ and the minimum cooling utility was $400 \mathrm{MW}$. The pinch point was identified at $60{ }^{\circ} \mathrm{C}$ which having zero heat flow. For process $\mathrm{B}$, the minimum hot utility required 
was $100 \mathrm{MW}$ and the minimum coolimg utility was $1543 \mathrm{MW}$. The pinch point for process $\mathrm{B}$ was at $195^{\circ} \mathrm{C}$. The pinch point determined in the Process A PTA and Process B PTA were used to construct the Multiple Utility - Problem Table Algorithm.

Based on the the MU-PTA for Process A constructed, it required 1,500 MW of hot utility, which consisted of $750 \mathrm{MW}, 200 \mathrm{MW}$ and 650 MW of HPS, MPS and LPS respectively. The cooling water required to satisfy excess heat source of $400 \mathrm{MW}$ from Process A was identified. For Process B, 100 MW of hot utility was required at the HPS level to satisfy Process B heat sink. The Process B excess heat source of $1543 \mathrm{MW}$ which consisted of $215 \mathrm{MW}$ at MPS level and 989 MW at LPS level. The remaining heat source was satisfied by cooling water.

The utility requirements for both Process A and Process B determined in the MU-PTA were summed up to determine Total Site energy requirement by constructing Total Site Problem Table Algorithm (TS-PTA) as shown in Table 3. Any excess utility generation at higher level was then cascaded to satisfy lower level energy requirement.

Table 3 Total Site Problem Table Algorithm (TS-PTA) result for case study.

\begin{tabular}{|c|c|c|c|c|c|c|c|c|}
\hline 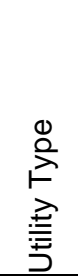 & 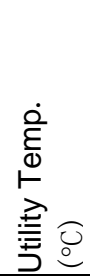 & 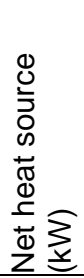 & 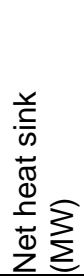 & 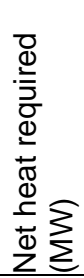 & 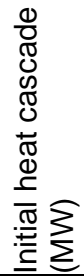 & 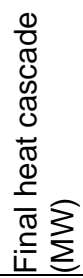 & 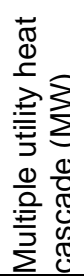 & 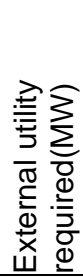 \\
\hline HPS & 270 & 0 & 850 & -850 & 0 & 850 & 0 & 850 \\
\hline MPS & 180 & 215 & 200 & 15 & 000 & 15 & 0 & -15 \\
\hline LPS & 134 & 989 & 650 & 339 & -496 & 354 & 0 & -33 \\
\hline CW & 15 & 739 & 0 & 739 & 243 & 1093 & 0 & -73 \\
\hline
\end{tabular}

The overall TS system required $850 \mathrm{MW}$ and 1,093 MW of hot and cooling utility from the utility system, which there were excess MPS, LPS and CW generation opportunities for $15 \mathrm{MW}, 339 \mathrm{MW}$ and 739 MW from the processes.

In this study, LPS has been defined as the low temperature waste heat source carrier in the TS energy system. The excess waste heat source with temperature more than the LPS temperature $134^{\circ} \mathrm{C}$ in the TS-PTA Table 3.3 was identified as the waste heat available for the integration with ORC and condensing turbine. The TS-PTA indicated for the heat source, there were $15 \mathrm{MW}$ of excess heat at MPS level and 339 MW of excess LPS generation. The 15 MW of MPS was then cascaded to the LPS level which generated $354 \mathrm{MW}$ of low temperature waste heat. Thus, there was $354 \mathrm{MW}$ of waste heat available for the integration with ORC and condensing Turbine.

\section{KEY STEP 2: Heat recovery technology integration}

The ORC model in this study was simulated using design conditions as in Aneke et al. (2011), which the working fluid was assumed to be R134A. The limitions of this ORC model were it was developed by using simple thermodynamic relations and did not able to simulate using multiple working fluids except R134A. The superheating inside the turbine was also not being considered. The simulation design conditions was decribed below.
The working fluid was entered the pump inlet at $12{ }^{\circ} \mathrm{C}$ with mass flowrate of $1656 \mathrm{~kg} / \mathrm{s}$ as saturated liquid where it was pressurized to the evaparator pressure of 16.95 bar. The temperature of working fluid was assumed to be increased by $1{ }^{\circ} \mathrm{C}$ from pump to the evaparator. In the evaparator, the working fluid was heated up to $65{ }^{\circ} \mathrm{C}$ at constant pressure by exchanging heat with the waste heat and left as saturated steam condition to the turbine for power generation with turbine isentropic efficiency of 0.80 . The working fluid was expanded in the turbine where pressure dropped to condenser pressure. The condenser pressure was set to pump pressure of 4.43 bar. The working fluid was condensed at constant pressure in the condenser, which was basically a heat exchanger, by rejecting heat to cooling utilities. The working fluid left the condenser as saturated liquid and entered the pump, completing the cycle.

For the ORC integration, the model was simulated by integrating $354 \mathrm{MW}$ of the low temperature waste heat into the ORC evaparator. The simulation result showed that the ORC generated 35.90 MW of power generation using pump power consumption of $4.74 \mathrm{MW}$. The net power generation of the ORC was $31.17 \mathrm{MW}$ with thermal efficiency of $0.088 \%$.

For the condensing steam turbine simulation, the turbine utilized steam with steam flowrate of $146.5 \mathrm{~kg} / \mathrm{s}$ to drive. The turbine pressure inlet was set to 2.25 bar with steam temperature of $134{ }^{\circ} \mathrm{C}$. The advantage of condensing steam turbine was its ability to accept a wide range of inlet pressure at the turbine compared to ORC, where the ORC working fluid characteristics were affected the system performance. The exhausted steam from the condensing turbine was at a pressure well below atmospheric at 0.15 bar, typically in $90 \%$ steam saturation. The condensing turbine model generated $45.61 \mathrm{MW}$ of power generation with the integration of $354 \mathrm{MW}$ waste heat.

The following assumptions were considered for the ORC model development:

- The ORC system was under steady state conditions

- Constant efficiencies were assumed for the pump and turbine

- The working fluid left the condenser as saturated liquid

- The temperature increase of $1^{\circ} \mathrm{C}$ from the pump to heat exchager was assumed

The condensing steam turbine simulation was performed based on following assumptions:

- The steam was exited the turbine outlet at $90 \%$ saturated steam condition

- The steam was superheated before entering condensing turbine

Table 4 ORC and steam turbine data.

\begin{tabular}{ll}
\hline Organic Rankine Cycle & \\
\hline Working fluid & $\mathrm{R} 134 \mathrm{~A}$ \\
Pump Isentopic efficiency & 0.35 \\
Turbine isentropic efficiency & 0.8 \\
$\mathrm{Q}_{\mathrm{H}}(\mathrm{kJ} / \mathrm{kg})$ & 354000 \\
\hline Steam Turbine & \\
\hline Working fluid & Steam \\
Turbine isentropic efficiency & 0.9 \\
$\mathrm{Q}_{\mathrm{H}}(\mathrm{kJ} / \mathrm{kg})$ & 354000 \\
\hline
\end{tabular}

\section{KEY STEP 3: Economic analysis}

In order to estimate the economic cost for ORC condensing turbine and base case, the processes in the TS system were assumed to operate for 335 day annually. Natural gas-fired boiler with efficiency of 0.75 was considered in the utility costing estimation. The electricity, fuel and cooling water prices were estimated at $0.1058 \$ / \mathrm{kWh}, 0.19 \$ / \mathrm{kg}$ and $0.0479 \$ / \mathrm{m}^{3}$. The total utility cost for Base Case was found to be 212.54 $\mathrm{M} \$ / \mathrm{y}$, with $188.51 \mathrm{M} \$ /$ year was spent for fuel and $24.03 \mathrm{M} \$ /$ year for cooling water. 
Table 5 Total cost comparision for base case, ORC case and steam turbine case.

\begin{tabular}{|c|c|c|c|}
\hline & $\begin{array}{l}\text { Base } \\
\text { Case }\end{array}$ & $\begin{array}{l}\text { Organic } \\
\text { Rankine } \\
\text { Cycle }\end{array}$ & $\begin{array}{l}\text { Condensing } \\
\text { Steam } \\
\text { Turbine }\end{array}$ \\
\hline HPS (MW) & 850 & 850 & 850 \\
\hline MPS (MW) & -15 & 0 & 0 \\
\hline LPS (MW) & -339 & 0 & 0 \\
\hline $\mathrm{CW}(\mathrm{MW})$ & -739 & -739 & -739 \\
\hline $\begin{array}{l}\text { Waste heat for ORC } \\
\text { Evaporator (MW) }\end{array}$ & 0 & 354 & 0 \\
\hline $\begin{array}{l}\text { Hot Utilities } \\
\text { Requirement (MW) }\end{array}$ & 850 & 850 & 850 \\
\hline $\begin{array}{l}\text { Cold Utilities } \\
\text { Requirement (MW) }\end{array}$ & 1,093 & 1062 & 739 \\
\hline $\begin{array}{l}\text { ORC Condenser Load } \\
\text { (MW) }\end{array}$ & 0 & 322.83 & 0 \\
\hline $\begin{array}{l}\text { Power Generation } \\
\text { (MW) }\end{array}$ & 0 & 31.17 & 45.61 \\
\hline Hot Utility Cost (M\$/y) & 188.51 & 188.51 & 188.51 \\
\hline $\begin{array}{l}\text { Cold Utility Cost } \\
\text { (M\$/year) }\end{array}$ & 24.03 & 23.34 & 16.25 \\
\hline $\begin{array}{l}\text { Power Cost Saving } \\
\text { (M\$/year) }\end{array}$ & 0 & 26.53 & 38.82 \\
\hline $\begin{array}{l}\text { Total Utility Cost } \\
\text { (M\$/year) }\end{array}$ & 212.54 & 188.53 & 165.94 \\
\hline
\end{tabular}

In the integration of ORC, the plant total utility costing was seen to be spent about $188.53 \mathrm{M} \$ /$ year for the hot utility, cold utility and also included the power saving. The power generation savings from the ORC was estimated to be worth of $26.53 \mathrm{M} \$$ /year, which was somewhat lower than condensing turbine. The cold utility cost was 23.34 M\$year.

The plant total utiltiy costing for the condensing turbine intgeration was estimated around $165.94 \mathrm{M} \$$ /year for the hot utility, cold utility and power saving. The plant total utlity costing was the lowest when compared to the ORC and base case, which the utility cost reduction was contributed by power generation savings where it has been generated profit worth of $38.82 \mathrm{M} \$ /$ year and low cold utility cost around 16.25 M\$/year.

\section{DISCUSSION AND CONCLUSION}

The condensing steam turbine showed a significance performance in power generation in comparison to ORC. The results indicated higher power saving and lower total plant utility costing for condensing steam turbine as compared to the ORC and base case. The leading power performance of condensing turbine was attributed by its principal advantage where turbine could generate high power output. The potential of condensing turbine for low temperature waste heat should be considered for future research for this reason. Integration of ORC system has lower power generation than condensing turbine, which resulting the plant total utility costing to be higher. However, this integration option was still feasible compared to the base case senario, which the utility cost reduction was obtained. In addition, the capital cost of the ORC and turbine system were not yet considered in the analysis.

The integration of the low temperature waste heat in processes site has been proven to improve the energy efficiency and energy saving through the extended TSHI methodology developed in this study. The integration of the ORC and condensing turbine with the processes site was feasible because it could simultaneously reduce-the hot utility and cooling utility requirements by utilizing the excess waste heat source for power generation. The implementation of this integration that was assisted by the methodology developed, the overall site energy consumption would be reduced and the efficiency in industrial sites could be enhanced, which contributing to economic and environmental sustainability.

The plant total utility costing of ORC could be reduced more by carrying out ORC optimization. The turbine pressure inlet of ORC in this study accounted only $40 \%$ of the working fluid critical pressure.
This study also showed that the cold utility costing was increased for ORC case in comparison to the base case. This was due to condenser heat release which required to be cooled down. For future study, the performance of ORC for waste heat recovery in process sites can be optimized further by exploring the potential of condenser heat for boiler feedwater preheating besides on the power generation.

\section{ACKNOWLEDGEMENT}

The authors appreciate the financial support from Universiti Teknologi Malaysia through Research University Grant. The first author would like to express his gratitude to Malaysia-Japan International Institute of Technology (MJIIT) in providing the student incentive throughout the research project.

\section{REFERENCES}

Aneke, M., Agnew, B., Underwood, C. (2011). Performance analysis of the Chena binary geothermal power plant. Applied Thermal Engineering, 31(10), 1825-1832.

Bendig, M., Maréchal, F., Favrat, D. (2013). Defining "Waste Heat" for industrial processes. Applied Thermal Engineering, 61(1), 134-142.

Cengel, Y. A., Boles, M. A. (2002). Thermodynamics: an engineering approach. Sea, 1000,8862 .

Desai, N. B., Bandyopadhyay, S. (2009). Process integration of organic Rankine cycle. Energy, 34(10), 1674-1686.

Klemeš, Dhole, V. R., Raissi, K., Perry, S. J., Puigjaner, L. (1997). Targeting and design methodology for reduction of fuel, power and $\mathrm{CO} 2$ on total sites. Applied Thermal Engineering, 17(8-10), 993-1003.

Liew, P. Y., Alwi, S. R. W., Varbanov, P. S., Manan, Z. A., Klemeš, J. J. (2012). A numerical technique for total site sensitivity analysis. Applied Thermal Engineering, 40, 397-408.

Liew, P. Y., Walmsley, T. G. (2016). Heat pump integration for total site waste heat recovery. Chemical Engineering Transactions, 52(2016), 817-822.

Oluleye, G., Jobson, M., Smith, R., Perry, S. J. (2016). Evaluating the potential of process sites for waste heat recovery. Applied Energy, 161, 627-646.

Oluleye, G., Smith, R. (2016). A mixed integer linear programming model for integrating thermodynamic cycles for waste heat exploitation in process sites. Applied Energy, 178, 434-453.

Pierobon, L., Nguyen, T.-V., Larsen, U., Haglind, F., Elmegaard, B. (2013) Multi-objective optimization of organic Rankine cycles for waste heat recovery: Application in an offshore platform. Energy, 58, 538-549.

Sun, W. Q., Yue, X. Y., Wang, Y. H. (2017). Exergy efficiency analysis of ORC (Organic Rankine Cycle) and ORC-based combined cycles driven by lowtemperature waste heat. Energy Conversion and Management, 135, 63-73.

Thekdi, A., Nimbalkar, S. (2014). Industrial Waste Heat Recovery:

Ulrich, G. D., and Vasudevan, P. T. (2006). How to estimate utility costs. Chem. Eng, 113(4), 66-69.

Varbanov, P., Doyle, S., and Smith, R. (2004). Modelling and optimization of utility systems. Chemical Engineering Research and Design, 82(5), 561578 . 